\title{
Isadore Max Tarlov (1905-1977) and the controversial Tarlov cyst: historical perspective
}

\author{
Subhas K. Konar, MD, MCH, Shyamal C. Bir, MD, PhD, Tanmoy K. Maiti, MD, MCH, \\ Papireddy Bollam, MD, and Anil Nanda, MD, MPH
}

Department of Neurosurgery, LSU Health-Shreveport, Louisiana

\begin{abstract}
Isadore Max Tarlov, an early neurosurgeon, made several important contributions to the field of spine surgery. He described sacral perineural cysts, now known as Tarlov cysts. Dr. Tarlov also introduced the knee-chest patient position to facilitate exposure and hemostasis in lumbar surgery. In addition, he developed the use of fibrin glue in nerve repair. His book on mechanisms of spinal compression was published in 1957. He published a book of essays titled Principles of Parsimony in Medical Practice that remains highly relevant in today's medical world.
\end{abstract}

http://thejns.org/doi/abs/10.3171/2015.5.SPINE1590

KEY WORDS Isadore Max Tarlov; perineural cyst; spinal injury; Tarlov cyst

$\mathrm{T}$ HE incidence of Tarlov cysts is estimated at approximately $5 \%$, but symptomatic cases constitute less than $1 \% .^{13}$ Tarlov cysts are most commonly diagnosed by lumbosacral MRI and can often be shown by CT myelography. Asymptomatic Tarlov cysts do not require treatment. Most perineural cysts are asymptomatic. Dr. Isadore Max Tarlov was the first person who described the spinal perineural cyst. This article is an attempt to reflect upon Dr. Tarlov's life and work.

\section{Biography}

Isadore Max Tarlov (Fig. 1) was born on May 16, 1905, in Norwalk, Connecticut, and spent his childhood there. He graduated from Norwalk High School in 1922. He went to Clark University in Worcester, Massachusetts, where he was elected to Phi Beta Kappa and graduated in 1926. As a student of Robert Goddard, pioneer of astronautics and one of the inventors of the rocket, Tarlov became interested in a scientific career. He obtained his medical degree from the Johns Hopkins Medical School in 1930, and then finished his training as a first resident under Wilder Penfield in neurosurgery at the Montreal Neurological Institute. Tarlov also had fellowships in neurosurgery at the University of Chicago with Percival Bailey and at Barnes Hospital in St Louis with Dr. Bernard Sachs. He married Fella Bechman in 1938. He studied the anatomy and pa- thology of the spinal nerves of the subarachnoid space and described the cysts of the sacral roots. In 1938, Dr. Tarlov described the cyst for the first time in his paper. ${ }^{19}$ Later, he published several articles on spinal cysts. During World War II, he introduced a method of gluing injured nerves together using blood plasma. In his 1969 text, The Principle of Parsimony in Medicine, he presented his insightful approach to the practice of medicine based on Oslerian concepts. Isadore Tarlov died in June 1977 at 72 years old in Brooklyn, New York. Dr. Tarlov's greatest legacy to his patients was his compassion and respect for them. ${ }^{4}$ In 2006 , a foundation was formed by a father of a young patient with a Tarlov cyst and a nurse/medical educator who was also a patient with a Tarlov cyst. The goal of the foundation is to promote knowledge of the Tarlov cyst. This foundation also provides a platform for all patients with Tarlov cysts to share their experiences.

\section{Description of the Tarlov Cyst by Dr. Tarlov}

In 1938, during dissection of 30 cadavers at the Montreal Neurological Institute, Dr. Tarlov described the presence of cysts in the posterior portion of the sacral root at the junction of the spinal ganglion in 5 patients. His description of sacral nerve root cysts contributed to acceptance of the study of the spine as a worthy endeavor. In his publication, he described the evolution of the perineural 


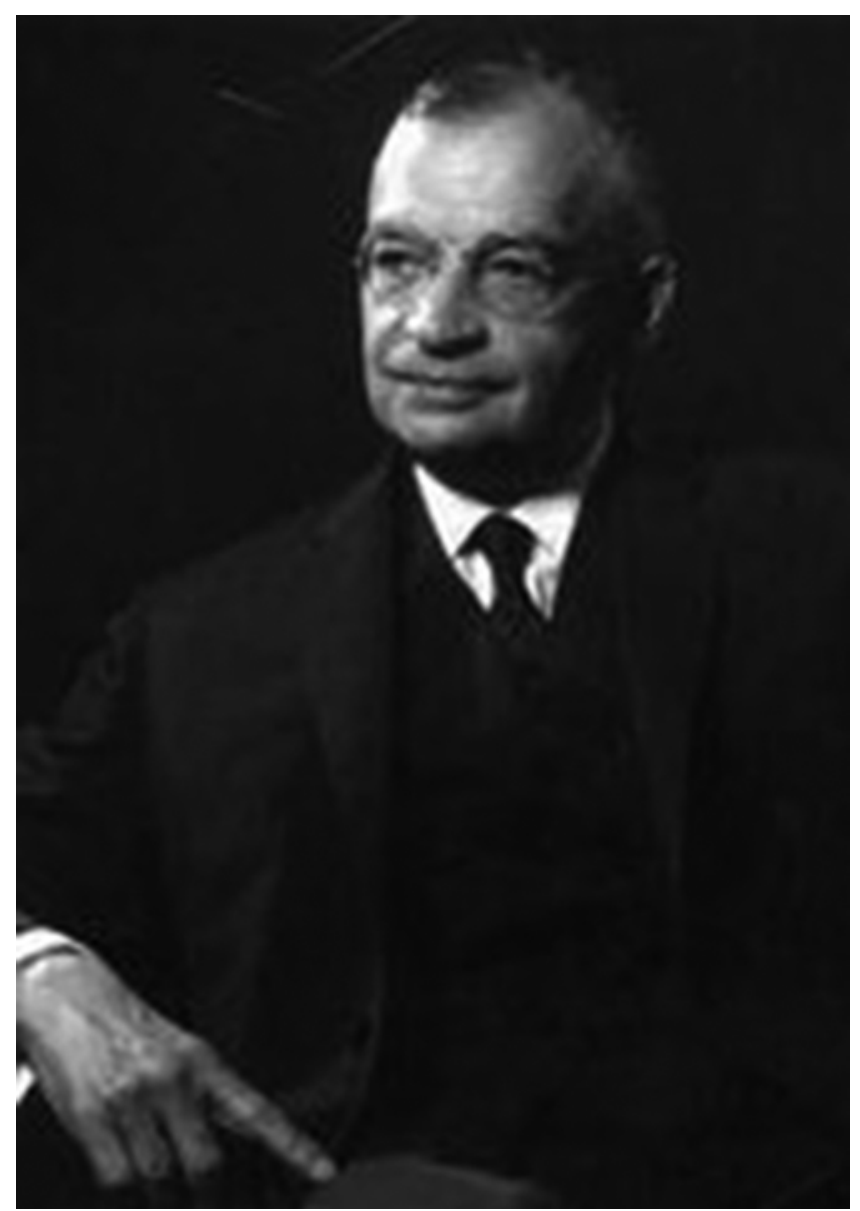

FIG. 1. Photograph of Dr. Isadore M. Tarlov. Image courtesy of Centro Integral de Ozonoterapia Medica, Jalisco, Mexico. cyst with its etiopathogenesis. He also showed the pathological basis of the cyst origin with serial histological sections (Fig. 2 [I]). He demonstrated the location of the cyst and its relationship to nerve roots (Fig. 2 [II]). Dr. Tarlov's comprehensive study on perineural sacral cysts introduced a new type of spinal cyst. ${ }^{19}$

\section{Other Contributions}

\section{Introduction of Fibrin Glue in Nerve Repair}

Although Bergel et al. ${ }^{3}$ introduced fibrin glue as a hemostatic agent in the early 20th century, Dr. Tarlov later popularized the use of fibrin glue in nerve repair. The technique was described in an animal study. The first step in this technique was dissection and cutting the sciatic nerves of rabbits, followed by keeping the cut end of the nerves as close as possible and depressing the end to form the trough. The next step was the addition of 5 drops of autologous plasma and 1 drop of autologous muscle tissue extract. The fluids were allowed to mix in situ, and to keep a lesser amount of the clot as suture material, about 3 drops were withdrawn into a pipette. Clot formation took 40 seconds but nerve ends were kept close for 4 minutes to make sure that the clotting process was complete. Separation of the nerve stumps was performed after confirming the strong tension on the suture line or poor tensile strength of the clot. Thirty percent of the operations were successful. ${ }^{21}$

\section{Introduction of the "Dry Surgical Field" in Spine Surgery}

Dr. Tarlov, in collaboration with William Cone in Montreal, demonstrated a unique "knee-chest position" in spine surgery (Fig. 3). This position was promising for
(I)

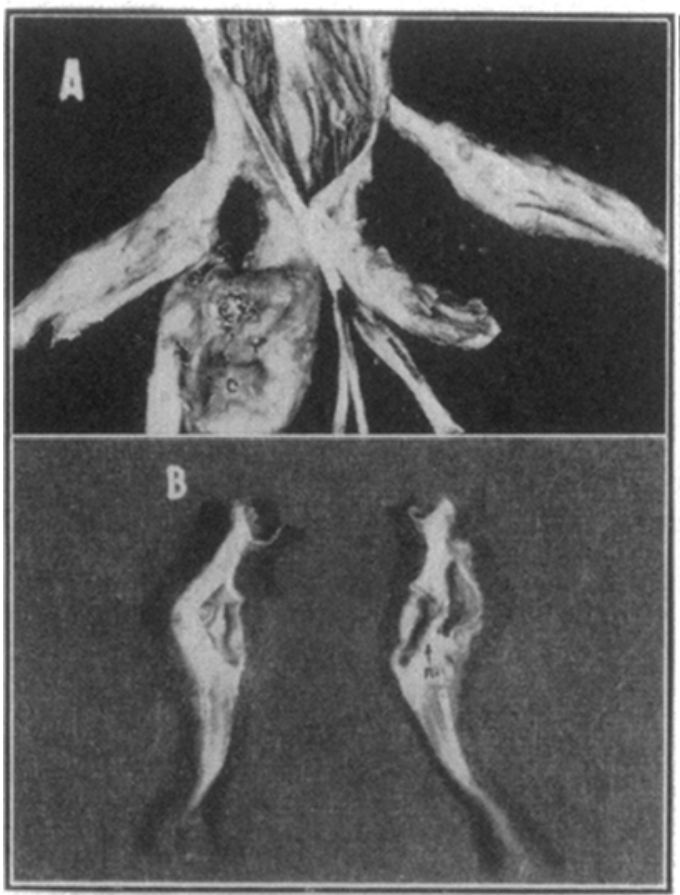

(II)

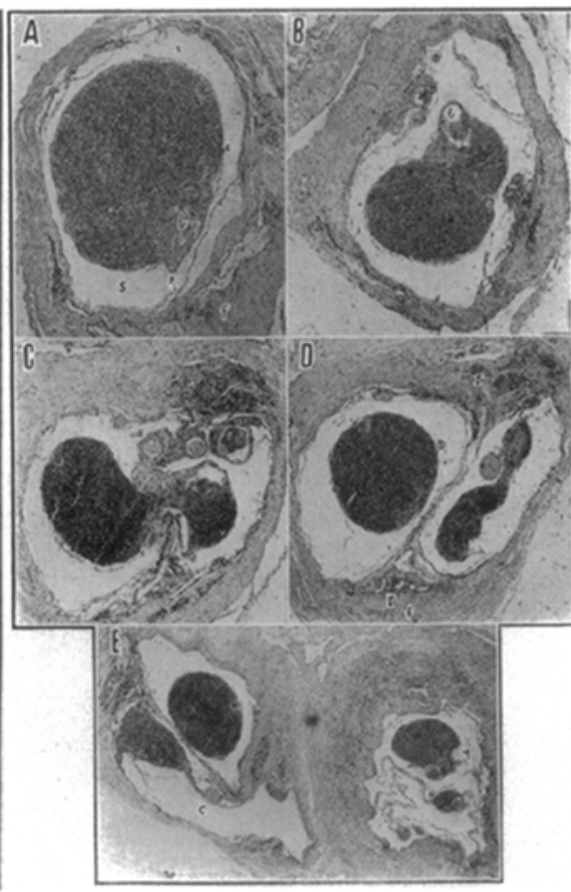

FIG. 2. I: Photographs showing the relationship of the cyst to nerve roots. A cyst (C) is shown at the lower sacral nerve roots $(\mathbf{A})$ and on the posterior sacral nerve root (B). Reproduced with permission from Tarlov: Arch Neurol Psych 40:1067-1074, 1938. II: Photographs showing the pathological basis of the cyst origin. A: Origin in the perineural space (s) between the endoneurium (e) and the perineurium (p). The epineurium (f) surrounds the perineurium. Large, thin-walled blood vessels (b) are located just under the endoneurium. B: Image showing an increase in the size of the cyst. C: Bifurcation of a bundle of nerve fibers, with the beginning of the formation of 2 cysts. Note the prominence of blood vessels adjacent to the cysts. D: Double cyst of a nerve root. Note the round cell infiltrations ( $r$ and $r$ ') in the epineurium. Infiltration may involve the perineurium. $\mathrm{E}$ : An increase in the size of a cyst (c) is shown. A bundle of nerve fibers is compressed at 1 side. There is early cyst formation (y) on an adjacent root. Reproduced with permission from Tarlov: Arch Neurol Psych 40:1067-1074, 1938. 


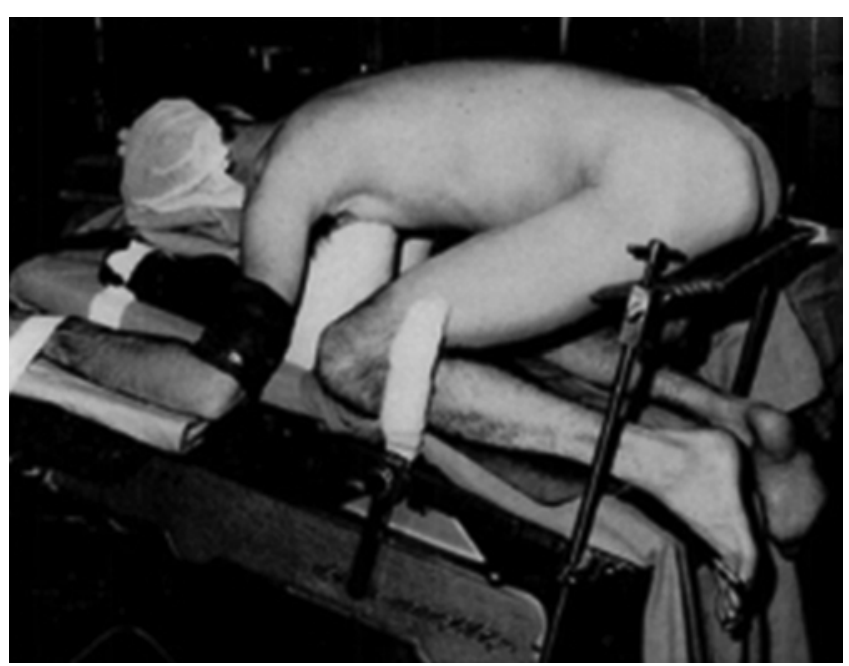

FIG. 3. Intraoperative photograph of the knee-chest position.

lower lumbar surgery. The advantage of this position is less compression on the chest and abdomen, leading to less pressure in epidural veins. The venous pressure can be further reduced if the head end of the table is kept low. This innovative positioning is still in use in spine surgery today. ${ }^{4}$

\section{Experimental Study on Mechanism of Spinal Cord Injury}

It was in 1954 that a pioneering animal study on dogs by Tarlov first established the benefit of early decompression in improving neurological outcome after spinal cord compression. ${ }^{25} \mathrm{He}$ demonstrated the various types of histopathological findings of spinal cord injury in relationship to the time frame of decompression. His experimental work on spinal cord injury was well received in the world neurosurgery forum regarding the timing of spinal decompression.

\section{Publications}

Dr. Tarlov was a pioneer of spine surgery and research related to the spine. He had numerous publications about spinal disorders and surgeries, including "Acute spinal cord compression paralysis." ${ }^{15}$ The early decompression of the spinal cord was advised by Dr. Tarlov for both incomplete and complete sensory motor paralysis. For incomplete compression, conservative treatment could be the first option, but if progressive neurological deterioration was noted then prompt laminectomy was indicated. In complete paralysis, if laminectomy was performed in a short interval then the outcome was promising. He also published several books on spinal cysts and nerve repair techniques, including Plasma Clot Suture of Peripheral Nerves and Nerve Roots; Rationale and Technique 21 and Sacral Nerve-Root Cysts; Another Cause of the Sciatic or Cauda Equina Syndrome; ${ }^{23}$ both publications were important contributions by Dr. Tarlov. In addition, he authored 57 published journal articles on various neurosurgical disorders, including experimental studies on spinal cord injury, peripheral nerve injuries such as brachial

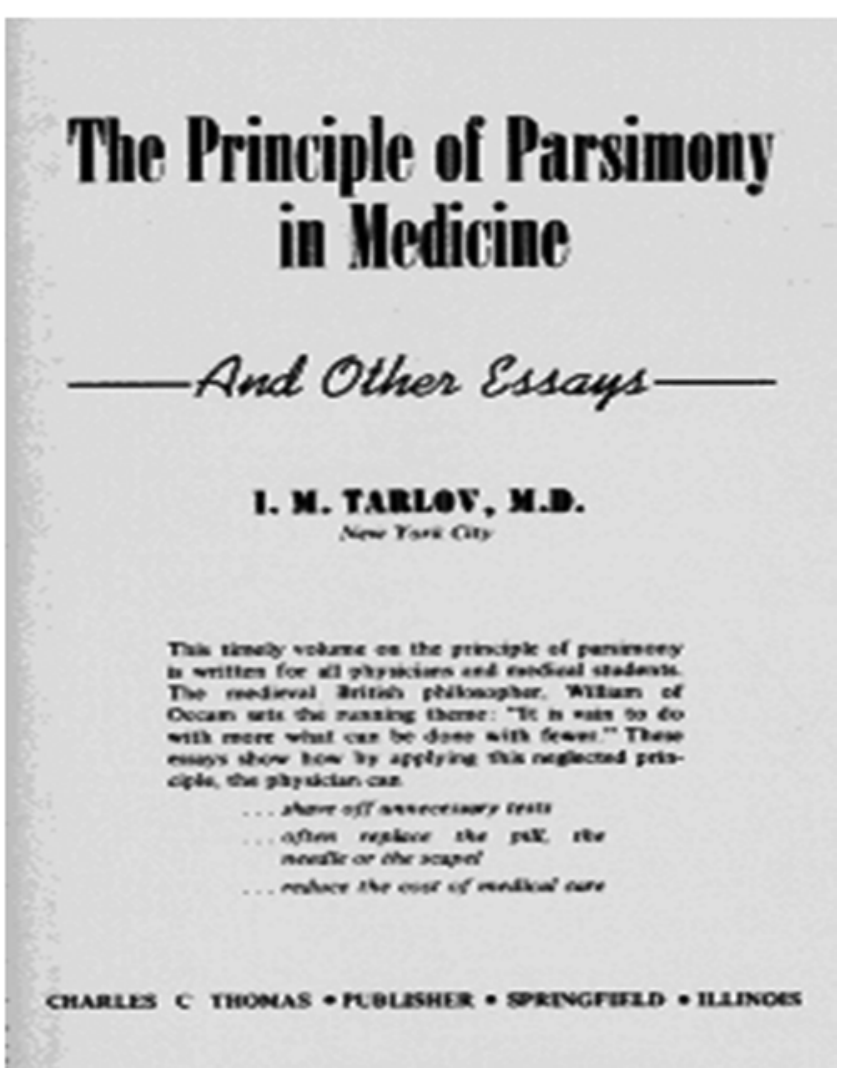

FIG. 4. Photograph of Dr. Tarlov's featured book, published in 1959. Image courtesy of the Burton Report Spine Hall of Fame Biographies.

plexus injury, and experimental neurography. ${ }^{24}$ In another notable publication, The Principle of Parsimony in Medicine $^{22}$ (Fig. 4), he expressed his insightful approach to the practice of medicine. He also conveyed his philosophical view in his article "The physician as teacher, student, and practitioner." 20

\section{Modern Concept and Treatment Options for Tarlov Cysts}

The etiology of "Tarlov cyst," a unique cyst of the nerve root sleeve, is unknown. Tarlov ${ }^{15,17,25}$ proposed that ischemic degeneration, inflammation, or hemorrhage, either infiltrating from the subarachnoid space or of traumatic origin, could lead to cyst formation. Other authors have suggested that Tarlov cysts form as a result of arachnoidal proliferation ${ }^{12}$ or an obstruction of perineural lymphatic tissue. ${ }^{6}$

Tarlov cysts are usually asymptomatic. Dr. Tarlov ${ }^{18}$ postulated that these cysts could cause sacral radiculopathy. Surgical intervention for Tarlov cysts is usually ill advised. Various nonoperative therapies include lumbar CSF drainage ${ }^{2,5}$ or CT-guided cyst aspiration, ${ }^{10,11}$ but neither of those treatments prevents symptomatic cyst recurrence. Neurosurgical techniques for symptomatic perineurial cysts include simple decompressive laminectomy, ${ }^{14}$ cyst and/or nerve root excision, ${ }^{9,26}$ and microsurgical cyst fenestration and imbrication. ${ }^{8}$ Acosta Jr. et al. ${ }^{1}$ reported a case 
of a symptomatic cyst managed with cyst fenestration, cyst wall resection, and closure with myocutaneous flap reinforcement to prevent cyst recurrence or CSF leakage. Lucantoni et al. ${ }^{7}$ reviewed the various management options of a cyst and their outcome. Numerous complications can follow surgical intervention, including perineal sensory loss, incontinence, CSF leak, and worsening pain.

\section{Conclusions}

This article acknowledges the legacy of Dr. Isadore Max Tarlov and his seminal work on the spinal cord. It also brings insight into Dr. Tarlov's innovative works on the spinal cord and motivates future neurosurgeons to take the initiative to develop their own innovations in neurosurgery.

\section{Acknowledgment}

We would like to thank Dr. Edward C. Tarlov for providing us valuable information about Dr. Isadore $\mathrm{M}$. Tarlov and the management of Tarlov cysts.

\section{References}

1. Acosta FL Jr, Quinones-Hinojosa A, Schmidt MH, Weinstein PR: Diagnosis and management of sacral Tarlov cysts. Case report and review of the literature. Neurosurg Focus 15(2):E15, 2003

2. Bartels RH, van Overbeeke JJ: Lumbar cerebrospinal fluid drainage for symptomatic sacral nerve root cysts: an adjuvant diagnostic procedure and/or alternative treatment? Technical case report. Neurosurgery 40:861-865, 1997

3. Bergel S: Uber Wirkungen des Fibrins. Deutsch med Wochenschr 35:633-665, 1909

4. Burton CV: Hall of fame biographies. The Burton Report. (http://www.burtonreport.com/infspine/HallFameBiosII.htm) [Accessed August 20, 2015]

5. Caspar W, Papavero L, Nabhan A, Loew C, Ahlhelm F: Microsurgical excision of symptomatic sacral perineurial cysts: a study of 15 cases. Surg Neurol 59:101-106, 2003

6. Dickenman RC, Chason JL: Cysts of dorsal root ganglia. Report of 29 cysts and review of literature. Arch Pathol 77:366-369, 1964

7. Lucantoni C, Than KD, Wang AC, Valdivia-Valdivia JM, Maher CO, La Marca F, et al: Tarlov cysts: a controversial lesion of the sacral spine. Neurosurg Focus 31(6):E14, 2011

8. Mummaneni PV, Pitts LH, McCormack BM, Corroo JM, Weinstein PR: Microsurgical treatment of symptomatic sacral Tarlov cysts. Neurosurgery 47:74-79, 2000

9. Nishiura I, Koyama T, Handa J: Intrasacral perineurial cyst. Surg Neurol 23:265-269, 1985

10. Patel MR, Louie W, Rachlin J: Percutaneous fibrin glue therapy of meningeal cysts of the sacral spine. AJR Am J Roentgenol 168:367-370, 1997

11. Paulsen RD, Call GA, Murtagh FR: Prevalence and percutaneous drainage of cysts of the sacral nerve root sheath (Tarlov cysts). AJNR Am J Neuroradiol 15:293-299, 1994
12. Rexed BA, Wennstrom KG: Arachnoidal proliferation and cystic formation in the spinal nerve-root pouches of man. $\mathbf{J}$ Neurosurg 16:73-84, 1959

13. Singh PK, Singh VK, Azam A, Gupta S: Tarlov cyst and infertility. J Spinal Cord Med 32:191-197, 2009

14. Siqueira EB, Schaffer L, Kranzler LI, Gan J: CT characteristics of sacral perineural cysts. Report of two cases. J Neurosurg 61:596-598, 1984

15. Tarlov IM: Acute spinal cord compression paralysis. J Neurosurg 36:10-20, 1972

16. Tarlov IM: Cysts (perineurial) of the sacral nerve roots: another cause of the sciatic or sacral cauda equina syndrome. J Neuropathol Exp Neurol 11:88-89, 1952

17. Tarlov IM: Cysts of the sacral nerve roots; clinical significance and pathogenesis. AMA Arch Neurol Psychiatry 68:94-108, 1952

18. Tarlov IM: Cysts, perineurial, of the sacral roots; another cause, removable, of sciatic pain. J Am Med Assoc 138:740-744, 1948

19. Tarlov IM: Perineurial cysts of the spinal nerve roots, Arch Neurol Psych 40:1067-1074, 1938

20. Tarlov IM: The physician as teacher, student, and practitioner. N Y State J Med 64:1769-1771, 1964

21. Tarlov IM: Plasma Clot Suture of Peripheral Nerves and Nerve Roots; Rationale and Technique. Springfield, IL: Charles C Thomas, 1950

22. Tarlov IM: The principle of parsimony in medical practice. $\mathbf{N}$ Y State J Med 59:2050-2052, 1959

23. Tarlov IM: Sacral Nerve-Root Cysts: Another Cause of the Sciatic or Cauda Equina Syndrome. Springfield, IL: Charles C Thomas, 1953

24. Tarlov IM, Berman D, Epstein J: Experimental neurography. Am J Roentgenol Radium Ther 64:974-988, 1950

25. Tarlov IM, Klinger H: Spinal cord compression studies. II. Time limits for recovery after acute compression in dogs. AMA Arch Neurol Psychiatry 71:271-290, 1954

26. Voyadzis JM, Bhargava P, Henderson FC: Tarlov cysts: a study of 10 cases with review of the literature. J Neurosurg 95 (1 Suppl):25-32, 2001

\section{Disclosure}

The authors report no conflict of interest concerning the materials or methods used in this study or the findings specified in this paper.

\section{Author Contributions}

Conception and design: Konar. Acquisition of data: Konar. Analysis and interpretation of data: Konar. Drafting the article: Konar. Critically revising the article: Konar, Bir, Maiti, Bollam. Reviewed submitted version of manuscript: all authors. Approved the final version of the manuscript on behalf of all authors: Nanda.

\section{Correspondence}

Anil Nanda, Department of Neurosurgery, LSU Health-Shreveport, 1501 Kings Hwy., Shreveport, LA 71130-3932. email: ananda@1suhsc.edu. 